\title{
Pengaruh Tekanan Lingkungan, Tekanan Pemegang Saham, dan Ukuran Perusahaan terhadap Kualitas Sustainability Reporting
}

\author{
Dicky Beryl Kholif Arrokhman' ${ }^{1}$ \\ Jurusan Akuntansi \\ Politeknik Keuangan Negara STAN, \\ Indonesia
}

\author{
Siswanto ${ }^{2}$ \\ Jurusan Akuntansi \\ Politeknik Keuangan Negara STAN, \\ Indonesia
}

\begin{abstract}
Surel: siswanto@pknstan.ac.id
ABSTRAK

Perusahaan dituntut untuk memiliki kinerja lingkungan dan sosial yang baik, di samping kinerja keuangannya. Pemangku kepentingan menuntut informasi tersebut dalam sebuah laporan yang dinamakan Sustainability Reporting. Besarnya ukuran dari sebuah perusahaan berbanding lurus dengan perhatian publik yang didapatkan sehingga perusahaan besar lebih mudah mendapat pandangan negatif dari publik. Untuk menjawab pandangan negatif tersebut, perusahaan akan memberikan informasi yang lebih transparan, termasuk mengenai kualitas Sustainability Reporting. Penelitian ini bertujuan untuk mengetahui pengaruh tekanan lingkungan, tekanan pemegang saham, dan ukuran perusahaan terhadap kualitas Sustainability Reporting. Analisis dalam penelitian ini dilakukan terhadap 22 perusahaan yang menjadi peserta ASRRAT dalam periode tahun20182020 yang dipilih menggunakan purposive sampling, sehingga diperoleh 66 observasi. Penelitian ini menggunakan model regresi logistik data panel. Hasil penelitian menunjukkan tekanan lingkungan dan ukuran perusahaan memiliki pengaruh positif terhadap kualitas Sustainability Reporting. Sementara itu, tekanan pemegang saham berpengaruh negatif terhadap kualitas Sustainability Reporting.
\end{abstract}

Kata Kunci: Kualitas Sustainability Reporting; Tekanan Lingkungan; Tekanan Pemegang Saham, Ukuran Perusahaan; Asian Sustainability Reporting Rating.

\section{Effect of Environmental Pressure, Shareholder Pressure, and Company Size on the Quality of Sustainability Reporting}

\begin{abstract}
Company to have goodenvironmental and social performance, besides its financial performance. Stakeholders demand this information in a report called Sustainability Reporting. The size of a company is directly proportional to the public attention received, so that largecompanies are more receptive to get negative views. To answer this view, the company will increase the transparency of its information, including Sustainability Reporting. This study aims to determine the effect of environmental pressure, shareholder pressure, and company size on the quality of Sustainability Reporting. This research was conducted on 22 companies that participated in ASRRAT in the period 2018-2020 which were selected using purposive sampling. This study uses a panel data logistic regression model. The results show that environmental pressures and company size have a positive influence on the quality of Sustainability Reporting. Meanwhile, shareholder pressure shows a negative effect on the quality of Sustainability Reporting.
\end{abstract}

Keywords: Quality of Sustainability Reporting, Environmental Pressure, Shareholder Pressure, Company Size, Asian Sustainability Reporting Rating.

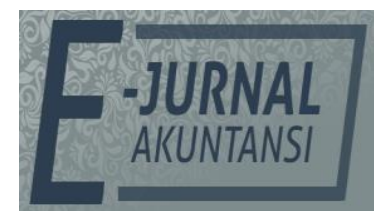

e-ISSN 2302-8556

Vol. 31 No. 12

Denpasar, Desember 2021 Hal. 3162-3177

DOI:

10.24843/EJA.2021.v31.i12.p10

PENGUTIPAN:

Arrokhman, D. B. K. \& Siswanto, S. (2021). Pengaruh

Tekanan Lingkungan,

Tekanan Pemegang Saham, dan Ukuran Perusahaan terhadap Kualitas Sustainability Reporting. EJurnal Akuntansi, 31(12), 3162-3177

RIWAYAT ARTIKEL: Artikel Masuk: 24 September 2021 Artikel Diterima: 31 Desember 2019

Artikel dapat diakses: https:/ /ojs.unud.ac.id/index.php/Akuntansi/index 


\section{PENDAHULUAN}

Dewasa ini, dalam bisnis global perusahaan tidak hanya dituntut untuk menghasilkan kinerja keuangan yang baik namun perusahaan juga harus memperhatikan kinerja lingkungan dan kinerja sosial (Sari, 2020). Film dokumenter berjudul "Sexy Killers" yang dirilis pada bulan April 2019 menggambarkan bagaimana aktivitas yang dilakukan oleh sebuah perusahaan yang memiliki dampak negatif bagi lingkungan dan masyarakat daerah sekitar perusahaan. Film yang diunggah di Youtube tersebut banyak ditonton dan dibicarakan oleh masyarakat sehingga meningkatkan kesadaran publik mengenai pentingnya kepedulian terkait permasalahan lingkungan dan sosial (Murfianti, 2020).

Hal tersebut menjadikan perusahaan dituntut untuk lebih transparan dan akuntabel atas dampak terhadap lingkungan dan sosial yang ditimbulkan dari aktivitas yang dilakukannya agar keberadaannya diterima masyarakat ata u public (Chang et al., 2019). Inge (2019) mengemukakan bahwa pertanggungjawaban ini juga dapat membuat citra yang baik bagi perusahaan dari masyarakat dan pemangku kepentingan. Bentuk pertanggungjawaban seperti ini sering dikenal sebagai Corporate Social Responsibility (CSR). Pertanggungjawaban ini harus bisa menjadi media pengomunikasian kepada pemangku kepentingan, untuk itu pemangku kepentingan menuntut adanya bentuk laporan dari pertanggungjawaban tersebut (Rudyanto \& Veronica, 2016). Dalam dunia akuntansi, laporan tersebut dikenal dengan istilah Sustainability Reporting.

Global Reporting Initiative yang selanjutnya disebut GRI (2016) mendefinisikan Sustainability Reporting sebagai sebuah laporan yang berpegang pada konsep three bottom lines, yakni People-Planet-Profit. People ditujukan untuk kinerja sosial, planet ditujukan untuk kinerja lingkungan, dan profit ditujukan untuk kinerja keuangan. Sustainability Reporting pertama kali dikenalkan oleh GRI pada tahun 1997. GRI ini juga yang mengeluarkan standar yang digunakan sebagai pedoman untuk membuat Sustainability Reporting. Indonesia mengembangkan Sustainability Reporting melalui National Center for Sustainability Reporting (NCSR) pada tahun 2005. Sustainability Reporting juga dapat digunakan untuk melihat kontribusi dari sebuah organisasi untuk mencapai Sustainable Development Goals (SDGs) (NCSR, 2018). Sejak 2015, SDGs merupakan kesepakatan dunia yang saat ini sedang dijalankan. Akan tetapi, dalam perkembangan praktiknya di Indonesia masih banyak perusahaan yang enggan untuk menerbitkan Sustainability Reporting yang mengindikasikan kegagalan Roadmap Keuangan Keberlanjutan yang diterbitkan Otoritas Jasa Keuangan (OJK) (Amidjaya \& Widagdo, 2019). Berdasarkan hal tersebut, pemerintah melalui OJK menerbitkan Peraturan OJK Nomor 51/POJK.03/2017 tentang Penerapan Keuangan Berkelanjutan Bagi Lembaga Jasa Keuangan, Emiten, dan Perusahaan Publik. Penerbitan peraturan ini juga dimaksudkan untuk menindaklanjuti hal yang telah diterbitkan oleh OJK pada tahun 2014 yakni roadmap keuangan berkelanjutan agar menjadi lebih efektif.

Kualitas dari pengungkapan keberlanjutan (Sustainability Reporting) akan sejalan dengan nilai perusahaan (Schadewitz dan Niskala, 2010), (Sari et al., 2017), (Loh et al., 2017). Hal ini berarti bahwa tingginya kualitas Sustainability Reporting akan membantu menaikkan nilai perusahaan. Kualitas Sustainability Reporting 
dapat ditentukan oleh standaryang digunakan untuk menyusun laporan tersebut. Menurut Loh et al. (2016) perusahaan yang menggunakan standar dari GRI sebagai pedoman untuk menyusunnya akan memiliki kualitas yang lebih tinggi.

Di Indonesia sendiri, perkembangan GRI standarnya diwadahi oleh NCSR yang di mana sejak tahun 2011 NCSR sudah menjadi mitra pelatihan resmi dari GRI. Sebagai wadah yang mengembangkan GRI standar, NCSR melakukan pemeringkatan terhadap kualitas Sustainability Reporting bernama Asia Sustainability Reporting Rating (ASRRAT) sejak tahun 2018, sebelumnya Sustainability Reporting Awards (SRA). Pemeringkatan yang mengategorikan Sustainability Reporting ke dalam peringkat dari tertinggi ke terendah berturutturut Platinum, Gold, Silver, dan Bronze itu merupakan satu-satunya pemeringkatan yang ada di Indonesia hingga saat ini (Darwin, 2019). Dikutip dari laman NCSR, pemberian rating yang dilakukan oleh NCSR ini merujuk pada kriteria-kriteria yang sudah ditetapkan, salah satunya mengenai penggunaan GRI standar. Pemeringkatan ini bisa juga dijadikan ajang evaluasi perusahaan guna meningkatkan kualitas Sustainability Reportingnya. Juara umum dari pemeringkatan ini berfluktuasi setiap tahunnya artinya kualitas dari Sustainability Reporting perusahaan peserta ASRRAT tidaklah konstan. Hal ini menimbulkan permasalahan mengenai faktor yang menentukan kualitas Sustainability Reporting.

Beberapa faktor yang diindikasikan dapat memengaruhi kualitas Sustainability Reporting antara lain adalah tekanan lingkungan, tekanan pemegang saham dan ukuran perusahaan. Tekanan yang diberikan oleh para pemangku kepentingan (stakeholders) menuntut perusahaan agar membuat Sustainability Reporting yang berkualitas (Rudyanto dan Veronica 2016). Suatu perusahaan memiliki tekanan stakeholder yang berbeda dengan perusahaan lainnya bergantung pada klasifikasi industrinya, meski begitu tekanan yang dilakukan stakeholder dari masing-masing klasifikasi akan dapat meningkatkan kualitas Sustainability Reporting (Feijoo et al., 2014). Sementara itu, jika dilihat dari teori stakeholder yang dikembangkan oleh Freeman (1984) menyatakan bahwa aktivitas yang dilakukan oleh perusahaan atau organisasi dipengaruhi oleh berbagai pemangku kepentingannya, bukan hanya pemegang saham saja. FernandezFeijoo et al. (2014) membagi stakeholder menjadi 4 kategori yaitu lingkungan, konsumen, pemegang saham, dan karyawan. Lebih lanjut Fernandez-Feijoo et al. (2014) menyatakan bahwa investor atau pemegang saham memiliki pengaruh yang paling tinggi terhadap terciptanya kualitas Sustainability Reporting. Film dokumenter "Sexy Killer" yang telah dipaparkan pada paragraf pertama mendapat banyak perhatian terutama dari para pencinta lingkungan. Hal ini menyebabkan para pencinta lingkungan menekan dan memaksa perusahaan untuk mempertanggungjawabkan kerusakan yang ditimbulkan oleh aktivitas yang dilakukan perusahaan (Murfianti, 2020).

Berdasarkan penjelasan pada paragraf, penelitian ini akan menggunakan variabel tekanan pemegang saham dan tekanan lingkungan. Selain variabel tersebut, penelitian ini juga akan menggunakan variabel ukuran perusahaan sebagai variabel yang akan diujikan terhadap kualitas Sustainability Reporting. Penelitian dengan menggunakan ukuran perusahaan sebagai variabelnya sudah banyak dilakukan (Dienes et al., 2016). Meski begitu yang mengaitkan hubungan 
ini dengan kualitas Sustainability Reporting masih sedikit dan hasil yang ditunjukkan juga kontradiktif.

Beberapa penelitian menyatakan bahwa perusahan yang besar akan memperoleh sorotan publik yang juga besar dibanding perusahaan kecil sehingga membuat kualitas Sustainability Reporting perusahaan besar akan lebih baik karena perusahaan akan berusaha menjaga citra mereka dari besarnya sorotan publik (Barung et al., 2018), (Rudyanto \& Veronica, 2016), (Privinka, 2020). Sedangkan, beberapa penelitian menyatakan bahwa perusahaan besar cenderung menahan informasi relevan dan hanya mengungkapkan informasi yang seperlunya (Aliniar \& Wahyuni, 2019), (Rakhman, 2017), (Zulaikha, 2017). Alasan tersebut membuat penulis tertarik untuk melakukan pengkajian ulang mengenai hubungan antara ukuran perusahaan dan kualitas Sustainability Reporting.

Beberapa penelitian sebelumnya yang memiliki kemiripan variabel dengan penelitian ini telah dilakukan namun masih memberikan hasil yang kontradiktif sehingga masih diperlukan adanya pengujian ulang untuk menentukan hubungan antara variabel ini. Tekanan dari para pencinta lingkungan mendorong perusahaan untuk mempunyai transparansi yang baik dalam hal Sustainability Reporting (Suharyani et al., 2019), (Rudyanto \& Veronica, 2016), (Sari, 2020). Di sisi lain, menurut Alfaiz \& Aryati (2019) serta Hamudiana \& Achmad (2017) dijelaskan bahwa meskipun perusahaan mendapatkan tekanan yang tinggi dari pencinta lingkungan, tekanan tersebut tidak akan membuat kualitas Sustainability Reporting menjadi baik. Dalam hal tekanan yang diberikan oleh pemegang saham juga terdapat kontradiksi pada penelitian-penelitian sebelumnya. Tekanan yang diberikan pemegang saham atau investor memiliki pengaruh yang kuat bagi perusahaan sehingga perusahaan cenderung meningkatkan transparansi Sustainability Reportingnya sehingga akan membuat investor memiliki kepercayaan lebih terhadap perusahaan (Hamudiana \& Achmad, 2017). Sementara itu, Alfaiz \& Aryati (2019) menyatakan bahwa dengan perusahaan mengungkapkan Sustainability Reporting yang berkualitas akan menimbulkan biaya lebih sehingga akan mengurangi return yang akan diterima oleh para investor. Berbeda dengan keduanya, Rudyanto \& Veronica (2016) serta Sari (2020) menyatakan bahwa tekanan yang diberikan oleh para pemegang saham tidak memberikan pengaruh apapun terhadap kualitas sustainabilty reporting dari suatu perusahaan.

Penelitian ini diharapkan mampu untuk memberikan hasil uji empiris yang baik mengenai hubungan antara tekanan lingkungan, tekanan pemegang saham, dan ukuran perusahaan terhadap kualitas Sustainability Reporting sehingga dapat digunakan sebagai referensi untuk penelitian-penelitian selanjutnya. Selain itu, hasil dari penelitian ini diharapkan dapat berkontribusi untuk memperbaiki kebijakan mengenai keberlanjutan yang sudah ada saat ini. Kemudian, perbedaan mendasar penelitian ini dengan penelitian-penelitian sebelumnya terletak pada penggunaan proksi dalam mengukur kualitas Sustainability Reporting. Penelitian ini juga menggunakan sampel perusahaan Indonesia yang menjadi peserta ASRRAT. Selain itu, penelitian ini juga menggunakan variabel umur perusahaan sebagai variabel kontrol.

Bagi perusahaan yang aktivitasnya berpotensi menyebabkan kerusakan lingkungan dengan menghasilkan polusi yang tinggi, lingkungan menjadi primary 
stakeholdernya. Feijoo et al. (2014) menyatakan bahwa perusahaan seperti ini dikategorikan sebagai Environmentally Sensitive Industries (ESI). Ditinjau dari teori stakeholder, perusahaan ini dituntut oleh pencinta lingkungan dan masyarakat setempat untuk mempertanggungjawabkan aktivitasnya yang berdampak negatif terhadap lingkungan. Selain itu, di Indonesia ada peraturan yang mengatur mengenai permasalahan lingkungan, yakni Peraturan Pemerintah Republik Indonesia Nomor 47 Tahun 2012 tentang Tanggung Jawab Sosial Dan Lingkungan Perseroan Terbatas. Berdasarkan teori legitimasi, perusahaan akan memberikan informasi mengenai tanggung jawab sosial dan lingkungannya dalam bentuk Sustainability Reporting sehingga keberadaan perusahaan akan diakui oleh pencinta lingkungan, masyarakat, dan pemerintah. Penelitian yang dilakukan oleh Rudyanto \& Veronica (2016) serta Sari (2020) menunjukkan tekanan yang diberikan oleh lingkungan memiliki pengaruh positif signifikan terhadap kualitas Sustainability Reporting. Sementara itu, penelitian Hamudiana \& Achmad (2017) serta Alfaiz \& Aryati (2019) menunjukkan bahwa tekanan lingkungan tidak memberikan pengaruh yang signifikan terhadap kualitas Sustainability Reporting. Mengacu pada penelitian Rudyanto \& Veronica (2016) serta Sari (2020), maka hipotesis penelitian ini adalah sebagai berikut.

$\mathrm{H}_{1}$ : Tekanan Lingkungan Berpengaruh Positif Signifikan terhadap Kualitas Sustainability Reporting.

Perusahaan yang menganggap investor sebagai primary stakeholder dikategorikan sebagai Investor-Oriented Industries (IOI). Bagi perusahaan yang memilik bentuk Perseroan Terbatas (PT), investor dikenal sebagai pemegang saham. Hal ini dikarenakan bukti dari penyertaan modal untuk perusahaan berbentuk PT adalah kepemilikan saham (Ndari, 2020). Sebagai penyedia modal bagi perusahaan, dukungan yang diberikan oleh pemegang saham sangat penting bagi perusahaan. Berkaitan dengan teori legitimasi, perusahaan akan melakukan aktivitas yang dapat menghasilkan dukungan dari pemegang saham. Hal ini dikarenakan dukungan dari pemegang saham dapat menjamin keberadaan perusahaan. Berdasarkan teori stakeholder, kekuatan yang dimiliki pemegang saham dapat digunakan oleh pemegang saham untuk menekan perusahaan sehingga perusahaan akan beraktivitas sesuai dengan keinginan pemegang saham. Tingginya tekanan pemegang saham dipengaruhi oleh tingkat penyebaran kepemilikan saham. Semakin besar tingkat penyebaran kepemilikan saham, maka tekanan dari pemegang saham juga akan semakin tinggi (Rudyanto dan Veronica 2016). Hal ini dikarenakan tingginya tingkat penyebaran kepemilikan saham, membuat pemegang saham dari perusahaan lebih beragam. Penelitian yang dilakukan oleh Hamudiana \& Achmad (2017) menunjukkan bahwa terdapat hubungan positif signifikan antara tekanan pemegang saham dan kualitas Sustainability Reporting. Hasil sebaliknya ditunjukkan oleh Alfaiz \& Aryati (2019) yang menyatakan bahwa tekanan pemegang saham dan kualitas Sustainability Reporting memiliki hubungan negatif signifikan. Sementara itu, Rudyanto \& Veronica (2016) serta Sari (2020) menyatakan bahwa tekanan pemegang saham tidak memiliki pengaruh signifikan terhadap kualitas Sustainability Reporting. Mengacu pada penelitian Hamudiana \& Achmad (2017), maka hipotesis penelitian ini adalah sebagai berikut. 
$\mathrm{H}_{2}$ : Tekanan Pemegang Saham Berpengaruh Positif Signifikan terhadap Kualitas Sustainability Reporting.

Teori legitimasi menyatakan bahwa aktivitas yang dilakukan perusahaan harus diterima oleh publik sehingga perusahaan dapat diterima keberadaannya. Sementara itu, teori stakeholder menyatakan bahwa perusahaan akan melakukan aktivitas sesuai dengan keinginan para stakeholdernya. Besar kecilnya suatu perusahaan dapat ditentukan dengan berbagai cara, salah satunya perhatian yang diberikan publik. Semakin besar suatu perusahaan maka akan memiliki pemangku kepentingan yang lebih besar dan lebih beragam pula sehingga perusahaan besar lebih memiliki kerentanan mengenai masalah negatif yang diberikan publik (Brammer \& Pavelin (dalam Rohman, 2019)). Permasalahan sosial dan lingkungan merupakan salah satu hal yang rentan mendapat dampak negatif dari publik. Untuk mengatasi hal tersebut, perusahaan perlu membuat sebuah Sustainability Reporting yang berkualitas sehingga akan mendapat legitimasi dari publik. Berkaitan dengan teori stakeholder, ketika perusahaan mengungkapkan Sustainability Reporting yang berkualitas maka perusahaan akan mendapatkan dukungan dari seluruh stakeholdernya (Chariri dan Ghazali, 2014). Dalam beberapa penelitian sebelumnya yang meneliti hubungan antara ukuran perusahaan dengan kualitas Sustainability Reporting, ukuran perusahaan dinyatakan berpengaruh positif signifikan terhadap kualitas Sustainability Reporting (Rudyanto \& Veronica, 2016), Barung et al., 2018). Berdasarkan hal tersebut, maka hipotesis dalam penelitian ini adalah sebagai berikut.

$\mathrm{H}_{3}$ : Ukuran Perusahaan Berpengaruh Positif Signifikan terhadap Kualitas Sustainability Reporting.

Berdasarkan ketiga hipotesis sebagaimana yang sudah dijelaskan, didasari teori stakeholder dari Freeman (1984) dan teori legitimasi dari Dowling dan Pfeffer (1975), maka kerangka berpikir penelitian ini digambarkan sebagai berikut.

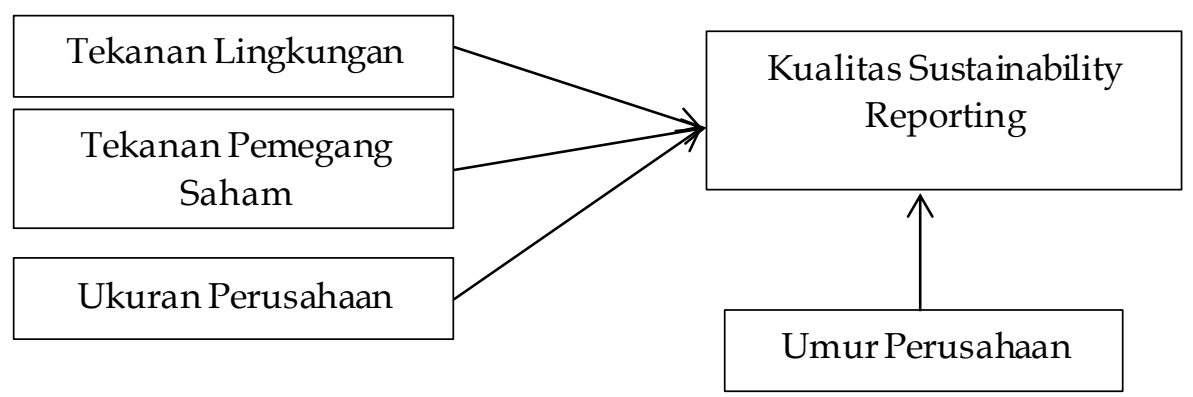

Sumber: Data Penelitian, 2021

\section{METODE PENELITIAN}

Penelitian ini merupakan penelitian jenis kuantitatif. Teknik yang digunakan untuk menganalisis data adalah statistik deskriptif dan statistik inferensial (Sugiyono, 2016). Pengujian model pada penelitian ini akan dilakukan dengan analisis regresi logistik. Hal ini dikarenakan variabel terikat yang digunakan memiliki bentuk dummy yang disesuaikan dengan kategori sehingga termasuk kedalam jenis variabel terikat non-metrik (Sekaran \& Bougie, 2016). Kepentingan utama dari penelitian ini adalah kualitas Sustainability Reporting. Berdasarkan 
laporan yang disampaikan Beretta dan Bozzolan $(2008,5)$ pengukuran kualitas Sustainability Reporting masih banyak diasumsikan sama dengan kuantitasnya. Padahal dibutuhkan sesuatu yang lebih sehingga pengguna Sustainability Reporting dapat melihat informasi dari berbagai macam perspektif yang akan sangat membantu pengguna tersebut dalam hal pengambilan keputusan (Helfaya et al 2019,4). Dalam penelitian ini penilaian akan dilakukan dengan cara memberi nilai pada kategori-kategori yang terdapat dalam kegiatan ASRRAT, yaitu nilai 1 akan diberikan untuk kategori Platinum dan Gold, sedangkan untuk kategori Silver dan Bronze akan diberikan nilai 0 .

Tekanan lingkungan merupakan tekanan yang diberikan oleh para pencinta lingkungan atau organisasi yang peduli lingkungan terhadap perusahaan dengan tujuan supaya perusahaan mempertanggungjawabkan perbuatannya yang berdampak negatif terhadaplingkungan. Perusahaan tersebut dikenal sebagai perusahaan yang termasuk dalam kelompok ESI. Skor 1 akan diberikan untuk perusahaan yang tergolong sebagai ESI, sedangkan untuk perusahaan selain ESI akan diberikan skor 0. Perusahaan yang tergolong ke dalam ESI adalah perusahaan yang bergerak di bidang agrikultur, pertambangan, industri kimia, mesin, otomotif dan komponennya, kabel, properti, perumahan, konstruksi, industri energi, jalan tol, lapangan terbang, pelabuhan, transportasi, konstruksi non bangunan, elektronik (Rudyanto dan Veronica, 2016).

Perusahaan yang memiliki pemegang saham sebagai primary stakeholder dikenal sebagai IOI. Tekanan pemegang saham diukur dengan menggunakan tingkat konsentrasi struktur kepemilikan. Tingkat konsentrasi struktur kepemilikan merupakan perbandingan jumlah saham yang dimiliki oleh perusahaan induk dengan jumlah saham keseluruhan (Rudyanto dan Veronica, 2016). Ukuran perusahaan merupakan besar kecilnya perusahaan berdasarkan kriteria tertentu. Variabel ini diukur menggunakan logaritma natural dari total aset (Barung et al., 2018). Penelitian ini juga menggunakan umur perusahaan sebagai variabel kontrol. Usia perusahaan diukur menggunakan tahun berdirinya perusahaan sampai dengan tahun laporan diterbitkan (Shamil et al., 2014).

Tabel 1. Pengukuran Variabel

\begin{tabular}{|c|c|c|c|}
\hline & Nama & Pengukuran & Sumber \\
\hline \multirow{4}{*}{$\begin{array}{l}\text { Variabel } \\
\text { Dependen }\end{array}$} & Kualitas & Platinum Gold =1 & \\
\hline & $\begin{array}{l}\text { Sustainability } \\
\text { Renortino }\end{array}$ & Silver, Bronze $=0$ & \\
\hline & Tekanan & $\mathrm{ESI}=1$ & Rudyanto \& \\
\hline & Lingkungan & Non-ESI $=0$ & Veronica (2016) \\
\hline \multirow[t]{2}{*}{$\begin{array}{l}\text { Variabel } \\
\text { Independen }\end{array}$} & $\begin{array}{l}\text { Tekanan Pemegang } \\
\text { Saham }\end{array}$ & $\begin{array}{l}\text { Jumlah saham perusahaan } \\
\text { induk/jumlah saham } \\
\text { keseluruhan }\end{array}$ & $\begin{array}{c}\text { Rudyanto \& } \\
\text { Veronica (2016) }\end{array}$ \\
\hline & Ukuran Perusahaan & Ln (Total Aset) & $\begin{array}{c}\text { Barungetal. } \\
(2018)\end{array}$ \\
\hline $\begin{array}{l}\text { Variabel } \\
\text { Kontrol }\end{array}$ & Umur Perusahaan & $\begin{array}{l}\text { Tahun berdiri perusahaan } \\
\text { sampai dengan tahun } \\
\text { laporan diterbitkan }\end{array}$ & $\begin{array}{l}\text { Shamil etal. } \\
\text { (2014) }\end{array}$ \\
\hline
\end{tabular}

Sumber: Data Penelitian, 2021

Berdasarkan data yang didapat, jumlah peserta ASRRAT untuk periode 2018-2020 adalah sebanyak 58 peserta. Proses eliminasi pertama dilakukan 
dengan cara mengeliminasi peserta yang tidak mengikuti ASRRAT secara keseluruhan periode 2018 -2020. Dari proses eliminasi ini didapat 34 peserta yang tidak mengikuti ASRRAT secara keseluruhan sehingga peserta yang selalu mengikuti ASRRAT adalah 24 peserta. Selanjutnya dilakukan eliminasi bagi peserta yang bukan merupakan perusahaan. Hal tersebut dikarenakan penelitian ini hanya menguji perusahaan. Peserta yang bukan merupakan perusahaan hanya ada 1 peserta. Terakhir, eliminasi dilakukan untuk peserta yang tidak menerbitkan laporan keuangan atau laporan tahunan terintegrasi dalam periode 2017 - 2019. Proses eliminasi ini dilakukan karena perusahaan tersebut tidak menyediakan data yang dibutuhkan untuk variabel dalam penelitian ini. Dari hasil eliminasi, terdapat 1 peserta yang tidak memenuhi kriteria ini sehingga sampel yang didapat untuk penelitian ini adalah sebanyak 22 peserta.

Dalam penelitian ini jumlah tahun yang digunakan sebanyak 3 tahun, yaitu dari tahun 2018 sampai dengan tahun 2020 yang membutuhkan data dari laporan keuangan atau laporan terintegrasi periode 2017 - 2019 untuk varibel penelitian. Untuk itu, jumlah observasi dalam penelitian ini sebanyak 66 observasi. Data yang dihasilkan dari pemilihan sampel memiliki sifat cross section (perusahaan) dan time series (tahun pengamatan) sehingga data yang digunakan merupakan data panel. Pengolahan data dalam penelitian ini menggunakan software statistika Eviews.

Tabel 2. Sampel Penelitian

\begin{tabular}{clc}
\hline No. & Kriteria & Total \\
\hline 1 & Jumlah peserta ASRRAT Periode 2018-2020 & 58 \\
2 & Jumlah peserta yang selalumengikuti ASRRAT Periode 2018-2020 & 24 \\
3 & Peserta yang bukan merupakan perusahaan & 1 \\
4 & Peserta yang tidak menerbitkan la poran keuangan atau laporan & 1 \\
$\quad$ tahunan periode2017-2019 & 22 \\
TotalSampel & 3 \\
Jumlah Tahun & 66 \\
Jumlah Observasi
\end{tabular}
Sumber: Data Penelitian, 2021

Berdasarkan penjelasan tersebut di atas, untuk mengetahui pengaruh dari tekanan lingkungan, tekanan pemegang saham dan ukuran perusahaan terhadap kualitas Sustainability Reporting dengan menggunakan umur perusahaan sebagai variabel kontrol, maka model penelitian ini akan memiliki bentuk sebagai berikut.

Keterangan :

$$
\operatorname{Ln}\left(\frac{\mathrm{SRQ}}{1-\mathrm{SRQ}}\right)=\mathrm{a}+\beta 1 \mathrm{X} 1+\beta 2 \mathrm{X} 2+\beta 3 \mathrm{X} 3+\beta 4 \mathrm{Z} 1+\varepsilon
$$

SRQ = Variabel Terikat Kualitas Sustainability Reporting

a $\quad=$ Konstanta

$\mathrm{X} 1 \quad=$ Variabel Bebas Tekanan Lingkungan

X2 = Variabel Bebas Tekanan Pemegang Saham

X3 = Variabel Bebas Ukuran Perusahaan

Z1 = Umur Perusahaan

$\varepsilon \quad=$ Error 


\section{HASIL DAN PEMBAHASAN}

Dalam penelitian ini, analisis statistik deskriptif yang disajikan berupa gambaran mengenai pemusatan data dan penyebaran data. Pemusatan data yang digunakan dalam penelitian ini adalah mean, yaitu nilai rata-rata dari jumlah nilai terhadap jumlah observasi. Sementara itu, untuk penyebaran data y ang digunakan adalah standar deviasi, nilai minimum, dan nilai maksimum. Standar deviasi menggambarkan seberapa dekat nilai data secara individu dengan rata-rata. Sedangkan nilai minimum dan nilai maksimum menggambarkan nilai terendah dan nilai tertinggi dari suatu data.

Tabel 3. Analisis Statistik Deskriptif

\begin{tabular}{lccccc}
\hline Variabel & Obs & Mean & Std.Dev. & Min & Max \\
\hline srq & 66 & 0,848 & 0,361 & 0 & 1 \\
esi & 66 & 0,772 & 0,422 & 0 & 1 \\
inv & 66 & 0,703 & 0,336 & 0 & 1 \\
Size & 66 & 31,693 & 1,421 & 29,492 & 34,887 \\
Age & 66 & 47 & 24,658 & 8 & 129 \\
\hline
\end{tabular}

Sumber: Data Penelitian, 2021

Rata-rata kualitas Sustainability Reporting (srq) yang diukur dengan variabel dummy menunjukkan nilai sebesar 0,848 . Tekanan lingkungan (esi) yang diukur menggunakan dummy memiliki rata-rata sebesar 0,772 . Tekanan pemegang saham (inv) yang diukur menggunakan perbandingan saham yang dimiliki oleh perusahaan induk terhadap total saham keseluruhan memiliki rata-rata sebesar 0,703. Ukuran perusahaan (size) yang diukur dengan menggunakan logaritma natural dari total asset memiliki rata-rata sebesar 31,693.

Software yang digunakan tidak mengakomodasi untuk dilakukan pengujian dalam pemilihan model seperti yang biasa dilakukan, yaitu Uji Chow, Uji Hausman, dan Uji Breusch-Pagan Lagrange Multiplier. Berdasarkan hal tersebut maka pemilihan model ditentukan dengan cara, apabila data panel yang diobservasi memiliki time series lebih besar dibandingkan cross section, maka FEM lebih tepat untuk dipilih. Sementara itu, apabila data panel yang diobservasi memiliki time series lebih kecil dibandingkan cross section, maka REM lebih tepat untuk dipilih (Ghozali, 2018:247). Dalam penelitian ini, time series yang ada dalam data panel berjumlah 3 , sedangkan cross sectionnya berjumlah 22. Penelitian ini memiliki cross section lebih besar daripada time series sehingga model yang dipilih untuk penelitian ini adalah REM.

Tabel 4. Matriks Korelasi Uji Multikolinearitas

\begin{tabular}{cccccc}
\hline Obs $=66$ & \multicolumn{7}{c}{} & & \\
\hline & srq & Esi & inv & size & age \\
\hline srq & 1,000 & & & & \\
esi & 0,477 & 1,000 & & & \\
inv & $-0,175$ & 0,059 & 1,000 & & \\
size & $-0,099$ & $-0,501$ & 0,182 & 1,000 & \\
age & $-0,031$ & $-0,231$ & 0,150 & 0,001 & 1,000 \\
\hline
\end{tabular}

Sumber: Data Penelitian, 2021

Menurut Gujarati dan Porter (2015) menyatakan bahwa agar variabel dapat dikatakan tidak memiliki korelasi yang tinggi, maka harus memiliki nilai di bawah 0,8. Berdasarkan Tabel 4, hasil matriks korelasi tidak ada yang 
menunjukkan nilai di atas 0,8 sehingga dapat disimpulkan bahwa data panel dalam penelitian ini terbebas dari masalah multikolinearitas.

Tabel 5. Model Tanpa Variabel Bebas dan Model Dengan Variabel Bebas

\begin{tabular}{|c|c|c|c|c|}
\hline \multirow{2}{*}{ Variabel } & \multicolumn{2}{|c|}{ MTVB } & \multicolumn{2}{|c|}{ MDVB } \\
\hline & Coef & Prob & Coef & Prob \\
\hline $\mathrm{C}$ & 2,552 & 0,003 & 8,024 & 0,004 \\
\hline esi & & & $-6,246$ & 0,067 \\
\hline inv & & & 1,599 & 0,026 \\
\hline size & & & 0,066 & 0,077 \\
\hline \multirow[t]{3}{*}{ age } & & & $-51,795$ & 0,030 \\
\hline & Prob > Chi2 & & Prob > Chi2 & \\
\hline & Log Likelih & 208 & Log Likelih & 4,787 \\
\hline
\end{tabular}

Sumber: Data Penelitian, 2021

Pengujian ini dilakukan untuk menguji apakah model lebih baik dengan atau tanpa variabel bebas (hanya konstanta). Model dikatakan lebih baik dengan menggunakan variabel bebas jika selisih -2LL dari model tanpa variabel bebas dan dengan variabel bebas lebih besar dari nilai chi-square tabel dengan degree of freedom sesuai jumlah parameter variabel bebas dalam signifikansi 5\% (Ghozali, 2016). Berdasarkan Tabel 5, diketahui bahwa nilai log likelihood (LL) dari model tanpa memasukkan variabel bebas atau hanya dengan konstanta adalah sebesar -26,208. Dengan begitu, maka -2LL dari model tanpa variabel bebas adalah sebesar 52,416. Sementara itu, nilai LL dari model dengan variabel bebas adalah sebesar -14,787 sehingga nilai -2LLnya sebesar 29,574. Berdasarkan hal tersebut dapat diketahui bahwa selisih -2LL dari model tanpa variabel bebas dan model dengan variabel bebas adalah 22,842 (52,416-29,574). Nilai chi-square tabel dengan degree of freedom 4 (jumlah parameter variabel bebas) adalah sebesar 9,488. Berdasarkan yang sudah dipaparkan, dapat disimpulkan bahwa model lebih baik dengan variabel bebas hal ini dikarenakan selisih -2LL dari model tanpa variabel bebas dan dengan variabel bebas lebih besar dari nilai chi-square tabel.

Kemudian dilakukan omnibus test yang mirip seperti uji $\mathrm{F}$ dalam model regresi linear biasa dengan tujuan untuk mengetahui pengaruh variabel bebas secara simultan (Fang, 2020). Hasil pengujian ini menunjukkan nilai prob>chisquare sebesar 0,036 (lihat Tabel 5). Dikarenakan nilai tersebut kurang dari signifikansi 0,05, maka dapat diartikan bahwa model ini fit atau variabel bebas secara simultan mempengaruhi model secara signifikan.

Tabel 6. Uji Goodness-of-Fit

\begin{tabular}{lc}
\hline Number of observations & 66 \\
Number of groups & 10 \\
Hosmer-Lemeshow chi2(8) & 3,29 \\
Prob $>$ Chi2 & 0,915 \\
\hline
\end{tabular}

Sumber: Data Penelitian, 2021

Model dapat dikatakan layak dan mampu untuk memprediksi nilai observasinya jika hasil dari Hosmer and Lemeshow's Goodness of Fit Test memiliki nilai signifikansi lebih dari $5 \%$ (Ghozali, 2016). Berdasarkan Tabel 6, hasil pengujin menunjukkan nilai prob>chi-square 0,9146. Dengan demikian, dapat disimpulkan bahwa model yang digunakan sudah fit atau dapat memprediksi nilai observasinya sehingga pengujian hipotesis dapat dilakukan menggunakan model ini. 
Tabel 7 : Klasifikasi Ketepatan Prediksi Model

\begin{tabular}{cccc}
\hline Classified & $\mathrm{D}$ & $\sim \mathrm{D}$ & Total \\
\hline+ & 53 & 4 & 57 \\
- & 3 & 6 & 9 \\
Total & 56 & 10 & 66 \\
& Correctly Classified & & $89,39 \%$ \\
\hline
\end{tabular}

Sumber: Data Penelitian, 2021

Berdasarkan Tabel 7, dapat diketahui bahwa nilai correctly classified sebesar $89,39 \%$. Hal tersebut dapat diartikan bahwa observasi yang dapat ditebak dengan tepat oleh model ini sebesar $89,39 \%$. Artinya, 59 observasi dari 66 observasi dapat ditebak dengan tepat.

Tabel 8. Uji Koefisien Determinasi

\begin{tabular}{lc}
\hline Prob $>$ Chi2 & 0,000 \\
Pseudo R2 & 0,473 \\
\hline
\end{tabular}
Sumber: Data Penelitian, 2021

Uji koefisien determinasi atau dikenal dengan R-squared $\left(\mathrm{R}^{2}\right)$ digunakan untuk menunjukkan seberapa besar kemampuan variabel bebas dalam menjelaskan variabel terikatnya (Pangestika 2015). Dalam regresi logistik, $R^{2}$ yang digunakan adalah Pseudo $\mathrm{R}^{2}$. Berdasarkan Tabel 7, diketahui bahwa Pseudo $\mathrm{R}^{2}$ menunjukkan nilai 0,473. Dengan begitu, dapat diartikan bahwa variabel bebas dalam model ini mampu menjelaskan variabel bebas, yaitu kualitas Sustainability Reporting sebesar 47,33\%, sedangkan 52,67\% dijelaskan oleh variabel lain di luar variabel bebas penelitian ini.

Tabel 9. Model Dengan Odds Rasio

\begin{tabular}{ccc}
\hline Variabel & OR & Prob \\
\hline C & 3056,324 & 0,004 \\
esi & 0,007 & 0,067 \\
inv & 4,948 & 0,026 \\
size & 1,068 & 0,077 \\
age & $3,20 \mathrm{e}-23$ & 0,030 \\
& Prob $>$ Chi2 $=0,036$ & \\
\hline & Log Likelihood $=-14,787$ & \\
\hline
\end{tabular}

Sumber: Data Penelitian, 2021

Pengujian signifikansi parameter secara individu dalam model regresi linear dilakukan menggunakan uji $t$, sedangkan dalam model regresi logistik dilakukan dengan uji z. Pengujian ini dimaksudkan untuk menguji signifikansi pengaruh dari variabel bebas secara individu terhadap variabel terikat. Dalam penelitian yang menggunakan model regresi logistik, nilai odds rasio perlu diperhatikan, yaitu besarnya kemungkinan variabel bebas mengubah variabel terikat. Jika nilai odds rasio lebih dari 1 (satu) maka variabel memiliki koefisien dengan tanda positif, sebaliknya jika nilai odds rasio kurang dari 1 (satu) maka variabel memiliki koefisien dengan tanda negatif (Rokhman, 2012). Menurut Stoltzfus (2011), hubungan odds rasio dan koefisien beta memiliki bentuk OR $=\mathrm{e}^{\beta}$ sehingga dapat diartikan bahwa setiap kenaikan 1 (satu) unit variabel bebas akan memperbesar kemungkinan hasil sebesar $\mathrm{e}^{\beta}$ kali. Pengujian dalam aplikasi STATA 14.0 menggunakan asumsi two-tailed hypothesis sehingga nilai probabilitas yang dihasilkan harus dibagi 2 (dua) mengingat hipotesis yang dibuat sudah menentukan arah (Field, 2009). 
Hasil pengujian mengenai pengaruh ukuran perusahaan terhadap kualitas Sustainability Reporting (lihat Tabel 9) menunjukkan bahwa ukuran perusahaan memiliki pengaruh signifikan dengan arah positif terhadap kualitas Sustainability Reporting. Dengan demikian, hasil pengujian tersebut tidak mendukung H3 yang diajukan dalam penelitian ini. Arah positif menunjukkan bahwa semakin besar ukuran perusahaan, maka Sustainability Reporting dari sebuah perusahaan akan semakin berkualitas. Hasil penelitian ini sejalan dengan penelitian (Barung et al., 2018). Ditinjau dari teori legitimasi, perusahaan akan cenderung mempertahankan reputasi yang dimiliki guna mendapatkan klaim dari publik sehingga perusahaan akan melakukan aktivitas yang dapat diterima oleh publik. Perusahaan besar memiliki tekanan yang juga besar dibandingkan dengan perusahaan kecil (Choi et al., 2013). Untuk menjawab tekanan tersebut, perusahaan dapat meningkatkan transparansi dalam mengungkapkan informasi yang dimilikinya. Hal tersebut bertujuan untuk memberi tahu kepada publik bahwa perusahaan telah bertindak sesuai dengan nilai yang ada sehingga perusahaan akan mendapat pengakuan dari publik. Dengan begitu, dapat dikatakan bahwa perusahaan yang dikategorikan sebagai perusahaan besar cenderung akan mengungkapkan informasi dengan lebih transparan untuk menjawab tuntutan dari publik. Hal ini berarti bahwa semakin besar ukuran perusahaan, maka akan semakin besar juga transparansinya dalam mengungkapkan informasi, termasuk informasi yang terkandung dalam Sustainability Reporting.

Teori stakeholder yang menyatakan bahwa aktivitas yang dilakukan perusahaan dipengaruhi oleh para pemangku kepentingannya mendukung hasil pengujian ini. Besarnya perusahaan sejalan dengan besarnya pemangku kepentingan. Artinya, semakin besar suatu perusahaan maka akan memiliki pemangku kepentingan yang semakin besar dan semakin beragam sehingga perusahaan besar cenderung akan memiliki kerentanan yang lebih tinggi mengenai masalah negatif yang diberikan publik dibanding perusahaan kecil (Brammer dan Pavelin (dalam Rohman, 2019)). Untuk mengurangi pandangan negatif yang diberikan publik, perusahaan besar akan mengungkapkan informasi yang lebih transparan (Jensen dan Meckling, 1976), termasuk dalam Sustainability Reporting. Dengan demikian, dapat disimpulkan bahwa semakin besar ukuran perusahaan, maka perusahaan akan cenderung meningkatkan kualitas Sustainability Reportingnya.

\section{SIMPULAN}

Berdasarkan hasil analisis regresi logistik, simpulan yang dihasilkan mengenai variabel-variabel yang diteliti adalah tekanan lingkungan dan ukuran perusahaan mempengaruhi kualitas Sustainability Reporting secara signifikan dengan arah positif. Sementara itu, tekanan pemegang saham memiliki pengaruh signifikan dengan arah negatif terhadapkualitas Sustainability Reporting. Keterbatasan dalam penelitian ini terletak pada kegiatan penganugerahan ASRRAT. Hal ini dikarenakan Kegiatan penganugerahan ASRRAT sampai penelitian ini dilakukan baru dilaksanakan selama 3 (tiga) tahun mulai tahun 2018 oleh NCSR dan jumlah perusahaan sampel yang terlalu sedikit karena menyesuaikan keikutsertaan perusahaan dalam kegiatan ASRRAT. Peneliti selanjutnya dapat menambah variabel lainnya untuk mengetahui faktor apa saja yang dapat mempengaruhi 
kualitas Sustainability Reporting dari sisi pemangku kepentingan, seperti tekanan konsumen dan tekanan karyawan; Menggunakan pengukuran dengan pengategorian lebih dari 2 (dua) kategori untuk mengukur kualitas Sustainability Reporting, misalnya nilai 0 untuk White, 1 untuk Bronze, 2 untuk Silver, 3 untuk Gold, dan 4 untuk Platinum; dan Melakukan uji mengenai perbedaan kualitas Sustainability Reporting sebelum dan sesudah diefektifkannya Peraturan OJK Nomor 51/PJOK.03/ 2017 sehingga dapat mengetahui efektivitas dari peraturan tersebut serta mengetahui aspek mana saja yang masih harus diperbaiki.

Investor diharapkan dapat mendorong perusahaan agar lebih transparan dalam mengungkapkan permasalahan sosial dan lingkungan. Ketika perusahaan mengungkapkan Sustainability Reporting yang memiliki kualitas tinggi, reputasi perusahaan juga meningkat. Peningkatan reputasi ini memperbesar peluang bagi investor untuk memperoleh return yang lebih tinggi di masa depan. Pemerintah melalui Kementerian Lingkungan Hidup dapat melakukan publikasi mengenai hasil PROPER secara masif seperti, melakukan kerja sama dengan influencer. Hal tersebut akan menjadikan perusahaan berlomba-lomba untuk meningkatkan kualitas tanggung jawab mengenai lingkungannya dengan cara beyond compliance guna menjaga reputasi yang dimilikinya. Pemerintah dapat memberikan reward bagi perusahaan yang memiliki kualitas Sustainability Reporting tinggi, misalnya tax holiday. Hal itu dapat membuat para pemegang saham akan menekan perusahaan agar mengungkapkan informasi yang lebih transparan dalam Sustainability Reporting karena akan menambah return yang disebabkan oleh reward dari pemerintah. Meskipun pemerintah sedang melakukan efiensi dalam anggarannya, akan tetapi pemberian reward tersebut akan berguna bagi pemerintah di masa mendatang.

\section{REFERENSI}

Alfaiz, D. R., \& Aryati, T. (2019). Pengaruh Tekanan Stakeholder Dan Kinerja Keuangan Terhadap Kualitas Sustainability Report Dengan Komite Audit Sebagai Variabel Moderasi. Jurnal Akuntansi Dan Keuangan Methodist 2(2):11230.

Aliniar, D., \& Wahyuni, S. (2017). Pengaruh Mekanisme Good Corporate Governance (GCG) Dan Ukuran Perusahaan Terhadap Kualitas Pengungkapan Sustainability Report Pada Perusahaan Terdaftar Di BEI. Jurnal Universitas Muhammadiyah Purwokerto 15(1):26-41.

Alotaibi, K. \& Hussainey, K. (2016). Quantity versus quality: The value relevance of CSR disclosure of Saudi companies. Corporate Ownership and Control, Volume 13, Issue 2.

Amidjaya, P. G., \& Widagdo, A. K. (2019). Sustainability Reporting in Indonesian Listed Banks: Do Corporate Governance, Ownership Structure and Digital Banking Matter?. Journal of Applied Accounting Research 21(2):231-47. doi: 10.1108/JAAR-09-2018-0149.

Beretta, S., \& Bozzolan, S. (2008). Quality versus quantity: The case of forwardlooking disclosure. Journal of Accounting, Auditing and Finance, 23(3), 333-375. https:/ / doi.org/10.1177/0148558x0802300304

Barung, M., Simanjuntak, A. M. A., \& Hutadjulu, L. Y. (2018). Pengaruh Mekanisme Good Corporate Governance Dan Ukuran Perusahaan Terhadap 
Kualitas Pengungkapan Sustainability Report (Studi Empiris Pada Seluruh Perusahaan Yang Listing Di Bursa Efek Indonesia Periode 2011-2016). Jumal Akuntansi \& Keuangan Daerah 13(November):76-89.

Chang, W. F., Amran, A., Iranmanesh, M., \& Foroughi, B. (2019). Drivers of Sustainability Reporting Quality: Financial Institution Perspective. International Journal of Ethics and Systems 35(4):632-50. doi:10.1108/IJOES-01-2019-0006.

Chariri, A., \& Ghazali, I. (2007). Teori Akuntansi. Semarang : Badan Penerbit Universitas Diponegoro.

Chariri, A, \& Ghazali, I. (2014). Teori Akuntansi. Semarang: Badan Penerbit Universitas Diponegoro.

Dewi, I. P., \& Pitriasari, P. (2019). Pengaruh Good Corporate Governance Dan Ukuran Perusahaan Terhadap Pengungkapan Sustainability. Jurnal Sains Manajemen \& Akuntansi Volume XI(1):21-39.

Dewi, N. P. R. C., Yudianti, F. N., \& Anggraini, R. R. (2019). Kualitas Assurance Statement Atas Sustainability Reports (Studi Empiris Di Indonesia). Jurnal Akuntansi Bisnis 12(2):148-71. doi: 10.30813/jab.v12i2.1776.

Dienes, D., Sassen, R., \& Fischer, J. (2016). What Are the Drivers of Sustainability Reporting? A Systematic Review. Sustainability Accounting, Management and Policy Journal 7(2):154-89. doi: 10.1108/SAMPJ-08- 2014-0050.

Dowling, J., \& Pfeffer, J. (1975). Organizational Legitimacy: Social Values and Organizational Behavior. Sociological Perspectives 18(1):122-36. doi: $10.2307 / 1388226$.

Fang, W. (2020). Cara Membaca Output SPSS Analisis Regresi Logistik. https:/ / www.youtube.com/ watch?v=lHIH6T7OZtg

Fernandez-Feijoo, B., Romero, S., \& Ruiz, S. (2013). Effect of Stakeholders' Pressure on Transparency of Sustainability Reports within the GRI Framework. Joumal of Business Ethics 122(1):53-63. doi: 10.1007/s10551- 013-1748-5.

Field, A. (2009). Discovering Statistics Using SPSS. In SAGE (3rd ed.). https:/ / doi.org/10.1190/1.1439489

Freeman, R. (1984). Strategic Management: A Stakeholders Approach. Boston: Fitman.

Ghozali, I. (2016). Aplikasi Analisis Multivariete Dengan Program IBM SPSS. Semarang: Badan Penerbit Universitas Diponegoro.

Ghozali, I. (2018). Aplikasi Analisis Multivariate Dengan Program SPSS 25 (9thed.). Semarang: Badan Penerbit Universitas Diponegoro.

Global Sustainability Standards Board. (2016). Rangkaian Standar Pelaporan Keberlanjutan GRI 2016 Terkonsolidasi. 444.

Gujarati, D. N., \& Porter, D. C. (2015). Dasar-Dasar Ekonometrika Edisi 5 Buku 2. Jakarta: Salemba Empat.

Hamudiana, A., \& Achmad, T. (2017). Pengaruh Tekanan Stakeholder Terhadap Transparansi Laporan Keberlanjutan Perusahaan-Perusahaan Di Indonesia. Diponegoro Journal of Accounting 6(4):226-36.

Helfaya, A., \& Whittington, M. (2019). Does designing environmental sustainability disclosure quality measures make a difference?. Business Strategy and the Environment, 28(4), 525-541. https:// doi.org/10.1002/bse.2262

Helfaya, A., Whittington, M., \& Alawattage, C. (2019). Exploring the quality of corporate environmental reporting: Surveying preparers' and users' 
perceptions. Accounting, Auditing and Accountability Journal, 32(1), 163- 193. https:/ / doi.org/10.1108/AAAJ-04-2015-2023

Hosmer, D. W., Lemeshow, S., \& Sturdivant, R. X. (2013). Applied Logistic Regression. New Jersey: John Wiley \& Sons, Inc.

$\mathrm{Hu}, \mathrm{M}$., \& Loh, L. (2018). Board Governance and Sustainability Disclosure: A Cross-Sectional Study of Singapore-Listed Companies. Sustainability (Switzerland) 10(7). doi: 10.3390/su10072578.

Jensen, M.C. \& Meckling, W.H. (1976) Theory of the Firm: Managerial Behavior, Agency Costs and Ownership Structure. Journal of Financial Economics, 3, 305360

Justin, P., \& Hadiprajitno, P. T. B. (2019). Pengaruh Struktur Dewan Direksi Terhadap Pengungkapan Laporan Keberlanjutan Perusahaan. Diponegoro Journal of Accounting 8(3):1-9.

Loh, L., Thi, N., Thao, T., Sim, I., Thomas, T., \& Wang, Y. (2016). Sustainability Reporting In Asean. Centre for Governance, Institutions \& Organitations NUS Business School.

Loh, L., Thomas, T., \& Wang, Y. (2017). Sustainability Reporting and Firm Value: Evidence from Singapore-Listed Companies. Sustainability (Switzerland) 9(11):1-12. doi: $10.3390 /$ su9112112.

Murfianti, F. (2020). Sexy Killer : Film And Environmental Movement. CAPTURE Jurnal Seni Media Rekam,48-62. https:/ / doi.org/10.33153/capture.v12i1.3209

Ndari, D. R. A. (2020). Pengaruh Kinerja Keuangan Dan Tekanan Stakeholder Terhadap Praktik Pengungkapan Sustainability Report Dengan Proporsi Komisaris Independen Sebagai Variabel Moderating. Skripsi. Semarang : Universitas Negeri Semarang.

Otoritas Jasa Keuangan. (2014). Roadmap Keuangan Berkelanjutan di Indonesia (2015 - 2019). OJK. Jakarta.

Otoritas Jasa Keuangan. (2017). Peraturan Otoritas Jasa Keuangan Nomor 51/POJK.03/2017 Tentang Penerapan Keuangan Berkelanjutan Bagi Lembaga Jasa Keuangan, Emitten Dan Perusahaan Publik. Ojk.Go.Id 1-15.

Otoritas Jasa Keuangan. (2017). Peraturan Otoritas Jasa Keuangan POJK No 53/POJK.04/2017 tentang Kewajiban Penyediaan Modal Minimum Bank Umum. Kewajiban Penyediaan Modal Minimum Bank Umum. Ojk.Go.Id 138.

Pangestika, S. (2015). Analisis Estimasi Model Regresi Data Panel dengan Pendekatan Common Effect Model (CEM), Fixed Effect Model (FEM), dan Random Effect Model (REM). Skripsi. Semarang : Universitas Negeri Semarang.

Rakhman, A. (2017). Pengaruh Karakteristik Perusahaan Terhadap Keputusan Penerapan Assurance Laporan Keberlanjutan (Studi Empiris pada Perusahaan yang Menerbitkan Laporan Keberlanjutan dan Terdaftar di Bursa Efek Indonesia Tahun 2012 - 2014). Skripsi. Karawang : Universitas Singaperbangsa Karawang.

Rohman, A. (2019). Analisis Pengaruh Kualitas Kinerja Berkelanjutan Perusahaan Dan Ukuran Perusahaan Terhadap Pengungkapan Keberlanjutan(Studi Empiris Pada Perusahaan Yang Terdaftar Di Bursa Efek Indonesia Tahun 
2015- 2017). Diponegoro Journal of Accounting 8(3):1-10.

Rokhman, M. S. (2012). Perbandingan Antara Model Logit dan Probit Sebagai Regresi Untuk Peubah Respon Kategori. Oseatek UPS Tegal.

Rudyanto, A., \& Veronica, S. (2016). Pengaruh Tekanan Pemangku Kepentingan Dan Tata Kelola Perusahaan Terhadap Kualitas Laporan Keberlanjutan. International Journal of Ethics and Systems 1-30.

Sari, N, A., Budi, A. dan Safriansyah (2017). Sustainability Report dan Nilai Perusahaan di Bursa Efek Indonesia. Jurnal Spread 7(1)

Sari, P. N. (2020). Determinan Kualitas Sustainability Report Perusahaan LQ45 Tahun 2017 dan 2018. Skripsi. Semarang : Universitas Negeri Semarang.

Schadewitz, H. and Niskala, M. (2010) Communication via Responsibility Reporting and Its Effect on Firm Value in Finland. Corporate Social Responsibility and Environmental Management, 17, 96-106.

Sekaran, U., \& Bougie, R. (2016). Reserach Methods for Bussiness : A Skill-Bulding Approach Seventh Edition. Wileypurposi, 7th Edition, 1-447.

Sugiyono. (2016). Metode Penelitian Kuantitatif, Kualitatif, dan R\&D. Bandung: Alfabeta.

Suharyani, R., Ulum, I., \& Jati, A. W. (2019). Pengaruh Tekanan Stakeholder Dan Corporate Governance Terhadap Kualitas Sustainability Report. Jurnal Akademi Akuntansi 8(5):55.

Trihatmoko, H., Ningsih, S., \& Mubaraq, M. R. (2020). Standalone Report, Assurance Report, GRI Reporting Framework Dan Kualitas Pengungkapan Sustainability Report. Keberlanjutan: Jurnal Manajemen Dan Jurnal Akuntansi 5(2):142. doi: 10.32493/keberlanjutan.v5i2.y2020.p142-156.

Wahyudi, U., \& Pawestri, H. P. (2006). Implikasi Struktur Kepemilikan Terhadap Nilai Perusahaan: dengan Keputusan Keuangan sebagai Variabel Intervening. Simposium Nasional Akuntansi 9. Padang: 1-25

Zulaikha, J. A. I. (2017). Assurance Laporan Keberlanjutan: Determinan Dan Konsekuensinya Terhadap Nilai Perusahaan. Diponegoro Journal of Accounting 6(2):103-16. 